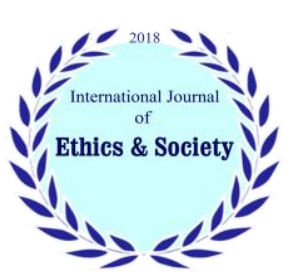

International Journal of Ethics \& Society (IJES)

Journal homepage: $\underline{\text { www.ijethics.com }}$

Vol. 3, No. 3 (2021)

(Original article)

\title{
Designing a Strategy Mixed Ethical Marketing in a Children's Book Based on the Parents' Purchase Intention
}

\begin{abstract}
Zahra Anjomshoaa
Dept. of Management, Faculty of Literature and Humanities, Kerman Branch, Islamic Azad University, Kerman, Iran
\end{abstract}

\section{Abstract}

Background: Ethical marketing strategy based on position analysis, identifies market opportunities and by defining different market segments and identifying the strengths and weaknesses of the organization, enables competition conditions. Designing a marketing strategy is one of the most important tasks of business planning for publishing companies. This study provides a model for designing a mixed ethical marketing strategy in a children's book based on the parents purchase intention.

Method: The research is applied in terms of purpose and descriptive-survey in terms of implementation method. The statistical population included the employees of cultural institutions that produce children's books. Sampling was done by simple random sampling and 110 people were selected as the statistical sample. The data collection tool was a mixed marketing ethics questionnaire and finally Friedman test was used to analyze and rank the data.

Results: The results finally led to a proposed model for explaining the C4 marketing mix strategy by highlighting the advertising element in line with the marketing strategy and the integration of the specific strategy of each mix.

Conclusion: Commitment to ethics in marketing and business creates a kind of trust that is a social and valuable capital and guarantees the long-term success of the relevant enterprises.

Keywords: Ethical marketing, Marketing strategy, Children's book, Parent purchase

* Corresponding Author: Email: zarianjom@yahoo.com

Received: 28 Apr 2021

Accepted: 12 Aug 2021

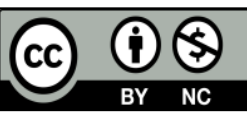

Copyright: (C) 2021 Anjomshoaa Z. Published by Iranian Association of Ethics in Science and Technology This article is an open access article distributed under a Creative Commons Attribution-Noncommercial 4.0 International License. (https://creativecommons.org/licenses/by-nc/4.0/ ). 


\section{Introduction}

Optimal allocation of scarce resources for the production and marketing of a new media product requires an in-depth understanding of marketing trends and accurate sales forecasting (1). Although it is difficult to predict sales of new products (2), business planning requires media executives to provide sales forecasts for new products for the future (3). In the publishing industry, sales forecasts for physical books are especially important in determining the number of printed copies. Excessively optimistic forecasts lead to overproduction, which is associated with additional printing costs, inventory, and disposal, which is associated with a detrimental environmental effect. However, ignoring the demand for cultural products means putting sales aside in a competitive market. As a result, a thorough understanding of the impact of various success factors in selling children's books identifying different buyer tendencies as well as forecasting sales for a new media product is an important task in business planning, which requires marketing strategy design $(1,2)$.

In this research, we deal with two neglected aspects in marketing research. The first is the large market for children's books. Children and adolescents' literature accounts for $16.5 \%$ of the total market revenue, of which only storybooks $(31.5 \%)$ have a larger market share (4). In Germany, the share of the children's book market in the book market is nine billion euros (5). The second is the lack of attention to ethical marketing. Careful and principled research is the best way to discover and predict the effects of a marketing strategy change in an industry. Ethical marketing is a process in which companies offer their goods and services to their customers not only by focusing on the profitability of products, but also the process of profitability in offering products with respect to social, environmental and cultural responsibilities (6).

Ethical marketers must be able to justify their decision to adopt this approach. In many companies, just knowing that ethical marketing is a good thing will not motivate you to do so. Therefore, the need to design a strategy in this area is essential. Another reason for the need to design a strategy is that the children's book market is theoretically particularly complex because there is a lot of uncertainty about the quality of the book due to the separation of customer (parent) and consumer (child) and children in terms of they are financially dependent on their parents. This complexity in strategy design is due to the fact that the intention to buy a children's book differs from the storybook market in the findings of previous studies, which usually relied on storybooks $(3,7,8)$.

In addition, books are commodities based on consumer experience, and consumers can only evaluate the quality of books after consumption (9). Because customers do not consider the book as a complete substitute for each other, consumers are faced with a wide range of options that make it difficult to choose the right books (7). This work has received special attention in this section due to the popularity of physical copies as well as giving as a gift as an incentive to buy (10).

A few research has studied the predictive models of new media products. Existing market response models usually depend on optimal profit, which depends on changes in marginal costs at the company level $(11,12)$.

Over the past decade, researchers have provided many frameworks for presenting marketing strategies through ideal types. Most of these patterns are designed and developed based on a rational (topdown) model. Rational models suggest one-way, top-down relationships. Although critics find these patterns logical, they find them unrealistic and believe that the requirements that determine marketing strategy are not exclusively upstream strategies, but other factors such as ethical and cultural factors in formulating effective marketing strategies (13).

Increasing patterns suggest interactive and two-way relationships, also known as natural (bottom-up) patterns. Recently, a combined approach of both rational and natural approaches has been proposed that has created a compatibility between these two approaches. This new approach is called strategic reference theory and states that by identifying the strategic reference points of the organization that 
have a major impact on the activities and performance of the organization, organizational elements (structure, culture, technology, strategy) can be designed based on them (1).

Unlike operational targets and benchmarks, strategic reference points are similar to strategic patterns and metrics because they are used to create core competencies at the system or organization level to help companies achieve a sustainable competitive advantage. Strategic reference points indicate to organizations what strategies and policies should be selected in each organizational element or system to align with the strategies and policies of other organizational elements. The selection of strategic reference points creates a strategic partnership to improve performance and achieve sustainable competitive advantage (14).

One of the newest theories of strategic management is strategic reference points (14). Experts in the theory of strategic reference points believe that one of the classic issues in the field of strategic management has been how to create and maintain coordination between external (environmental) needs and internal (organizational) resources (15). A reference point is a place or point where all measurements and choices are weighed against it. Setting benchmarks sets out the overall priorities of the system and incorporates them into the strategy so that stakeholders are guided by the principles.

Different theorists, each based on their own views, have listed specific reference points for the success of companies and commercial establishments. Cost reduction, quality, speed, innovation, customer and stakeholder needs are some of the points that, according to their theorists, if each of these points is emphasized, commercial companies will succeed (16-22).

Of course, some other theorists have used multidimensional and hybrid strategic reference points. The use of these combination points led to the emergence of strategic types and varieties. Three well-known and common categories of strategic reference points that exist in the management literature are:

- Presenting four paradigms for the analysis of social science theories in general and organizational and managerial theories in particular using the two-default philosophical and sociological reference points of change (23).

- Combining three perspectives on the theoretical models of organizations and providing a framework. Society for categorizing theories of organization and management using two reference points of type of organization and type of system (23).

- Presenting an effectiveness model and a set of values using two reference points of the organization's focus and the amount of control (24).

In this research, the third theory has been used and to find strategic reference points and typology of ethical marketing strategy in the matrix of strategic reference points, reference points have been used based on Hall's view (two dimensions of attention to inside / outside and low (flexible) control). Based on this and based on the research marketing model, ethical branding strategy was used to formulate the strategy (21), which is shown in Figure 1.

The purpose of this study is to adhere to the ethics in marketing and businesses related to children's books, which created a kind of trust that this issue is a valuable social capital and guarantees the longterm success of the relevant enterprises.

In this research, we have tried to ignore two aspects that have been neglected in marketing research, one is the large market of children's books, in which very little research has been done in Iran. To do this in this area should be given great importance.

\section{Material \& Methods}

The present study is an applied development research in terms of segmentation of research based on purpose and a descriptive survey research in terms of methodological classification. The statistical population of this study includes the employees of cultural institutions active in the field of children's books in Iran. Sampling was done by simple random sampling. Based on this, 110 people were selected as a statistical sample. Adequacy of sample size was determined according to statistical power (0.96), which indicates that the sample size is sufficient. According to the results, men accounted for $67 \%$ of the sample size, while women accounted 
for $33 \%$ of the sample size. Among the sample, the highest participation rate was related to the age between 50-60 years with a participation rate of $48 \%$. Between 40 and 50 years old and 11 people were over 60 years old. 5 people with 10 to 15 years of work experience, 34 people with more than 20 years of work experience, 37 people with 15 to 20 years of work experience and finally 4 people with 5 to 10 years of work experience. In this study, a mixed ethics marketing questionnaire from the perspective of customers was used (21). All of the collected questionnaires could be analyzed. Friedman test was used to rank the components of strategy.

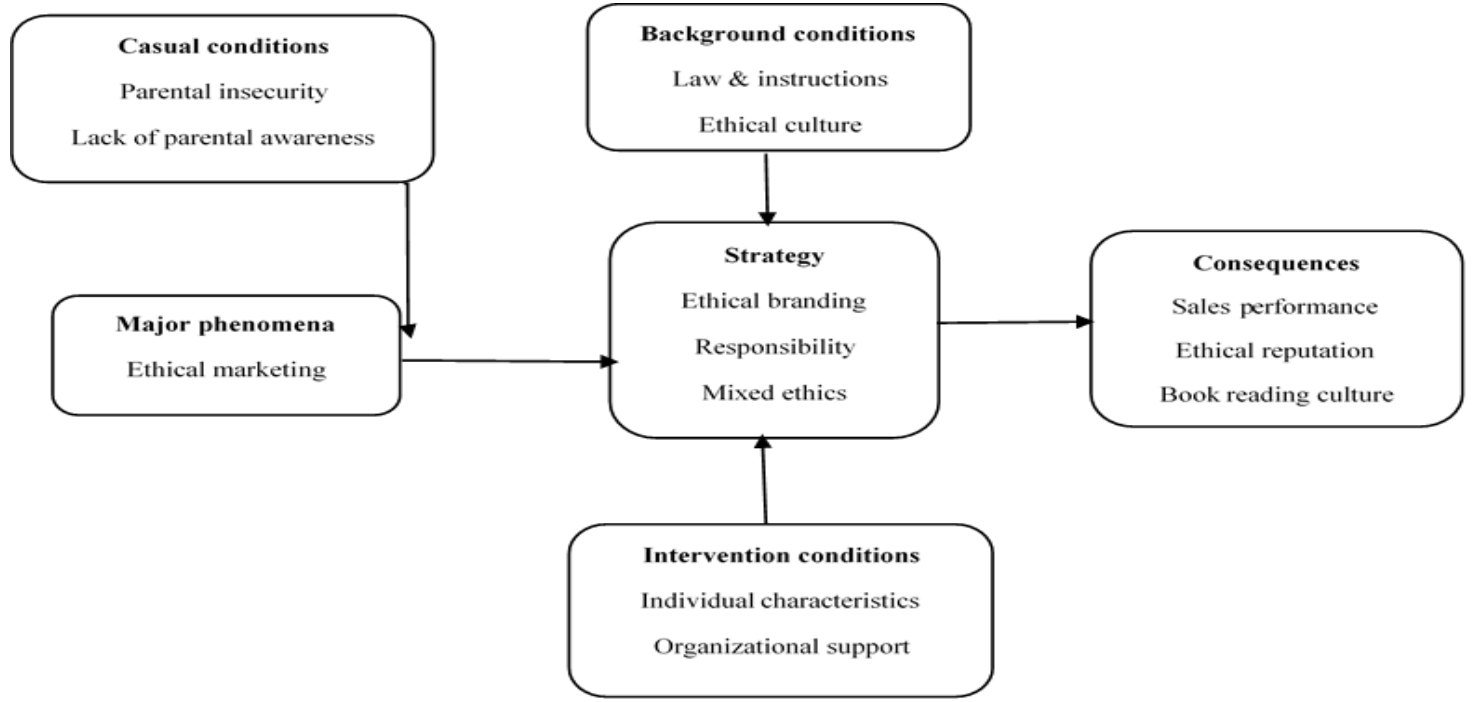

Fig 1: Ethical marketing model for children's books (21)

\section{Results}

In this study, according to the characteristics and characteristics of variables and their relationships as well as questionnaire questions, for each subscale, the sum of scores related to its items was calculated and then its average score was obtained. Then, the mean scores of each of the subscales related to a particular scale were compared with each other and the mean, the value of which was significantly different from the others, was selected. Table 1 lists the descriptive statistics of the research variables.

Table 1: Descriptive statistics of components of ethical marketing strategy

\begin{tabular}{|c|c|c|c|c|c|c|c|}
\hline & Mean & Median & Min & Max & SD & Kurt & Skew \\
\hline Ethical marketing & 12.003 & 12 & 5 & 18 & 2.706 & -0.528 & -0.245 \\
\hline Customer's values & 8.928 & 9 & 3 & 15 & 2.317 & -0.495 & -0.168 \\
\hline Cost & 18.181 & 18 & 9 & 28 & 3.313 & -0.213 & 0.19 \\
\hline Ethical culture & 12.134 & 12 & 5 & 20 & 2.478 & -0.101 & 0.038 \\
\hline Ethical reputation & 14.909 & 15 & 5 & 23 & 3.186 & -0.022 & -0.07 \\
\hline Ads & 20.797 & 21 & 11 & 20 & 3.338 & -0.051 & -0.257 \\
\hline
\end{tabular}

Based on the results obtained, the ranking of each component based on the weight obtained in the Friedman test can be ranked as follows: In poor condition

- Advertising

- Ethical reputation
- Ethical culture

- Customer values

- Cost

- Ethical marketing

In average mode

- Customer values 
- Ethical reputation

- Advertising

- Ethical marketing

- Cost

- Ethical culture

In strong condition
- Customer values

- Cost

- Advertising

- Ethical culture

- Ethical marketing

- Ethical reputation

Table 2: Ranking of components involved in the strategy for different modes

\begin{tabular}{|c|c|c|c|c|c|c|}
\hline Ranking & Weak & Sig. & Average & Sig. & Strong & Sig. \\
\hline Ethical marketing & 0.37 & 0.040 & 4.40 & 0.031 & 3.18 & 0.000 \\
\hline Customer's values & 1.77 & 0.033 & 8.45 & 0.050 & 7.54 & 0.049 \\
\hline Cost & 1.50 & 0.002 & 2.58 & 0.051 & 7.34 & 0.012 \\
\hline Ethical culture & 3.71 & 0.046 & 0.07 & 0.030 & 6.85 & 0.012 \\
\hline Ethical reputation & 8.60 & 0.003 & 7.51 & 0.001 & 2.85 & 0.001 \\
\hline Ads & 9.12 & 0.032 & 5.61 & 0.047 & 6.98 & 0.004 \\
\hline
\end{tabular}

According to the explanations given in the analysis section, the output of the computational process mentioned was the assignment of the dominant code of the ethical marketing strategy to each of the products. The details of the calculations are similar to what was said about the ethical marketing strategy, i.e. the final results of the quantitative- qualitative computational process have been done separately for all elements of the marketing mix. According to the frequencies extracted from the questionnaires in each area, the dominant components of the ethical marketing strategy are described in Table 3.

Table 3. Dominant combinations of strategies

\begin{tabular}{|c|c|c|c|c|c|c|}
\hline \multirow[t]{2}{*}{ Codes } & \multicolumn{6}{|c|}{ Strategies } \\
\hline & $\begin{array}{c}\text { Ethical } \\
\text { marketing }\end{array}$ & Customer's values & Cost & $\begin{array}{l}\text { Ethical } \\
\text { culture }\end{array}$ & Ethical reputation & Ads \\
\hline 11 & Decline & Focus & Reduction in costs & Sort & Neither traction nor thrust & ATL \\
\hline 22 & Introduction & Market development & Influence & Wide & Stretch & BTL \\
\hline 33 & Maturity & Diversification & Based on competitors & Selection & Thrust & TTL \\
\hline 44 & Growth & Product development & Low final cost & Exclusive & Both traction / thrust & TTL \\
\hline
\end{tabular}

In the next stage, the alignment and integration of the selected strategies in the field of ethical marketing and the ethical marketing mix were examined and tested according to their unified strategic reference points.

\section{Discussion}

The aim of this study was to design a mixed ethical marketing strategy in children's books based on the intention of parents to buy. Marketing is a social and managerial process by which individuals and groups meet their needs and wants through the production, supply and exchange of useful and valuable goods with others. The results showed that the first type of ethical marketing strategy, which is in the field of declining markets, with the first type of customer value strategy (focus strategy), the first type of mixed customer cost strategy (cost reduction strategy), the first type of channel strategy (expansion of ethical culture strategy), the strategy of the first type of moral reputation (strategy neither traction nor thrust) and finally with the strategy of the first type of propaganda coordinated and integrated and this integration has led to augmentation. This result consistent with the result of other studies (18).

The second type of ethical marketing strategy for children's books, which is in the field of market introduction and market entry, with the second 
type strategy of values and customer solutions (market development strategy), the second type strategy mixed with customer costs (penetration strategy), the second type of culture strategy ethical (wide strategy), the second type of strategy, moral reputation (traction strategy) and finally with the second type of advertising strategy (informative strategy and BTL type) have been coordinated and integrated, and this integration has led to augmentation. This result is consistent with the results of other researches $(1,2,5)$. Since consumers are the turning point of marketing activities in the field of cultural products, a successful marketing strategy begins with understanding why and how consumers behave. In this regard, market development strategy and traction strategy play a key role in the second type of ethical marketing strategy.

The third type of ethical marketing strategy is located in the field of mature markets that it is integrated with the strategy of the third type of values, customer's cost, ethical culture, ethical reputation and ads. This result is consistent with the results of other researches $(12,14,17)$. The third type of marketing strategy shows that we must pay attention to the nature of the cultural products industry, because the continuation of the activities of companies offering cultural products requires customer orientation and customer retention; In other words, diversification strategy and consolidation strategy have a significant role.

The fourth type of ethical marketing strategy is located in the field of growing markets that it is integrated and coordinated with the fourth type of values, customer's cost, ethical culture, ethical reputation and ads. This result is consistent with the results of research (23-25). The concept of marketing mix has a significant place in the marketing literature. There is a lot of criticism of the common marketing mix, especially in the field of services. Therefore, the present study aimed to provide an ethical model of marketing strategy for cultural products because the challenges of environmental change must be accompanied by identifying the needs of consumers.

The use of a mixed ethics strategy leads to the provision of services that, in addition to financing the organization in economic activities, are culturally and ideologically acceptable based on the principles of ethical marketing and are appropriate to individual and social values $(26,27)$.

The present study has some limitations. One of these limitations is that the tools of this research have not been designed in the country, although its validity and reliability have been evaluated, but it is possible that components that have influenced the research have been neglected. Also, the results are based on the answers of the participants and their answers to the questions are derived from their personal perception of the questions and are influenced by individual characteristics such as experience, knowledge and marketing motivation, which is suggested in future research as a factor. Be considered a strategy maker. It is also suggested that the performance and combination of strategies designed in different other markets be compared with the results of this study.

\section{Conclusion}

Commitment to ethics in marketing and business creates a kind of trust that is social capital and valuable and guarantees the long-term success of the relevant enterprises. On the other hand, many of the troubles associated with the operation of companies and firms are due to the lack of ethical commitment of economic agents, including firms, households and governments, misinformation about services, products, inaccurate statistics and reports, and thousands of similar examples of ethical disregard. It is a business that is important and vital due to the intense competition in attracting resources and retaining old customers. Given the importance of ethical marketing in businesses, especially in the production of cultural products, we can expect that by developing the ethics and ethical actions among companies operating in this sector, we can expect the excellence of society and with this excellence to improve ethical marketing in provide future business courses.

Uncertainty of parents 'decision-making along with parents' lack of awareness in the field of nontextbooks are considered as major categories in the field of causal conditions. Lack of information 
transparency, consumer concern about the consequences of shopping, uncertainty about shopping tips for parents as micro-categories, uncertainty of parents 'decision-making and poor awareness, poor reading literacy among parents were identified as micro-categories of parents' lack of awareness in this study. This suggests that what appears to be the cause of the emergence and importance of a concept such as ethical marketing in the nontextbook publishing industry first goes back to the issue of parental decision uncertainty. When parents enter the space of buying extracurricular books for their children, they face some kind of worry about their purchase. Concerns about choosing non-textbooks are generally raised in the sense that parents feel that the content of nontextbooks is not useful and age-appropriate. The feeling that buying non-textbooks is in fact a costeffective outlet for children, along with the inability to nurture talent and creativity among children, makes parents realize that these non-textbooks are not useful and suitable for their children. However, the use of ethical approaches can play a good role in the field of reassurance for parents. Studies have shown that consumer uncertainty stems from past perceptions that parents perceive in relation to non-textbook sellers. In communication, what is obvious is that the lack of ethical approaches causes sellers to focus only on selling and making a profit, and there may not be the right guidance that fits the real needs of the consumer, which undoubtedly increases consumer uncertainty. On the other hand, it should be noted that consumers are not aware. In ethical approaches, correct and purposeful information was tried to be continuously disseminated among parents in the field of nontextbooks, and the seller tries to provide correct knowledge to parents in communication, which can provide awareness in the space of buying nontextbooks and lack of awareness.

\section{Ethical Consideration}

The researcher ensures that in all stages of conducting research and preparing research reports, the principles of research ethics such as full observance of participants' rights, honesty and scientific fidelity, truth-seeking, etc., as well as ethical issues such as; Plagiarism, informed consent; duplications, etc. have been considered in the present study.

\section{Conflict of Interest}

The authors declare that there is no conflict of interests.

\section{References}

1. Dorfman R, Steiner PO (2014). Optimal advertising and optimal quality. The American Economic Review, 44(5): 826836.

2. Hirschman EC, Holbrook MB (1982). Hedonic consumption: Emerging concepts, methods and propositions. Journal of Marketing, 46(3): 92-101. Doi: https://doi.org/10.1177\%2F002224298204600314

3. Hofmann-Stölting C, Clement M, Wu S, Albers S. (2017). Sales forecasting of new entertainment media products. Journal of Media Economics, 30(3): 143-171. Doi: https://doi.org/10.1080/08997764.2018.1452746

4. Zeinali M. (2020). Book market statistics in 2019. Available at: https://www.ima.ir/news/83758238/ Accessed: 29 April 2021.

5. Börsenverein des deutschen Buchhandels (2019). Buch und Buchbandel in Zablen. Frankfurt am Main 'Germany. (In German).

6. Pia A, Albinsson bidisha burman G, David S, StoddardJE (2020). Integrating and assessing student perceived sustainability literacy in an integrated marketing communications course. Marketing Education Review, 30(3): 159-176. Doi: https://doi.org/10.1080/10528008.2020.1770102

7. Barrot C, Becker JU, Clement M, Papies D (2015). Price elasticity for hardcover and paperback fiction books. Schmalenbach Business Review, 67(1): 73-91. Doi: https://doi.org/10.1007/BF03396924

8. Beck J (2007). The sales effect of word of mouth: A model for creative goods and estimates for novels. Joumal of Cultural Economics, 31(1): 5-23. Doi: https://doi.org/10.1007/s10824-006-9029-0

9. Shapiro C, Varian HR (1999). Information rules: A strategic guide to the network economy. Boston Massachusetts: Harvard Business Press.

10. Leitão L, Amaro S, Henriques C, Fonseca P (2018). Do consumers judge a book by its cover? A study of the factors that influence the purchasing of books. Journal of Retailing and Consumer Senvices, 42: 88-97. Doi: https://doi.org/10.1016/i.jretconser.2018.01.015 
11. Kanuri VK, Mantrala MK, Thorson E (2017). Optimizing a menu of multiformat subscription plans for ad-supported media platforms. Journal of Marketing, 81(2): 45-63. Doi: https://doi.org/10.1509\%2Fjm.15.0372

12. Mantrala MK, Naik PA, SridharS, Thorson E (2007). Uphill or downhill? Locating the firm on a profit function. Journal of Marketing, 71(2): 26-44. Doi: https://doi.org/10.1509\%2Fimkg.71.2.026

13. Köhler C, Mantrala MK, Albers S, Kanuri VK (2017). A meta-analysis of marketing communication carryover effects. Journal of Marketing Research, 54(6): 990-1008. Doi: https://doi.org/10.1509\%2Fjmr.13.0580

14. Fiegenbaum A, Harts S, Shendel D (2006). Strategic reference point theory. Strategy Management Journal, 17(3).

15. Eskafi A (2005). Organization based on strategic reference points. [M.A thesis]. Allame Tabatabaei University, Iran/Tehran. (In Persian).

16. Porter MP (2010). Finance for strategic decision making. John Wiley \& Sons, Inc/USA.

17. Emayee GP (2011). Strategic financial management. Vikas Publishing House PVT Ltd, USA.

18. Stack CA, Houdd T (2012). Speed-marketing: a new strategy for fast decision-making. Advances in Management, 5(11).

19. Foster $S$ (2016). Organizational, technical and data quality factors in CRM adoption - SMEs perspective. Industrial Marketing Management, 40: 376-383. Doi: https://doi.org/10.1016/j.indmarman.2010.08.006
20. Uhmay DJ (2017). A multi-layered approach to CRM implementation: An integration perspective. European Management Joumal, 28: 153-180. Doi: https://doi.org/10.1016/i.emj.2009.04.010

21. Anjomshoaa Z, Hassanpour E, Bagheri M, Ranjbar MH (2019). Designing and explaining the ethical marketing model and its consequences for children in the field of non-textbooks. Ethics in Science and Technology, 14(5): 69-79. (In Persian). Dor: http://dorl.net/dor/20.1001.1.22517634.1398.14.5.11.8

22. Henderson T (2019). Performance comparison based on customer relationship management using analytic network process. Expent Systems with Applications, 38: 9788-9798. Doi: https://doi.org/10.1016/j.eswa.2011.01.170

23. Burrell G, Morgan G (1979). Sociological paradigm and onganirational analysis. Heinemann, London.

24. Scott W'T (1981). Organizations: rational, natural, and open system. Prentice Hall Inc, New Jersey.

25. Hall RH (2012). Organization: structures, process \& outcomes. Prentice Hall Inc, New Jersey.

26. Beigpour Tanha M, Namamian F, Taghvai R, Ghobadi Lamoki T (2020). Designing a normal model of ethical marketing in the hotel industry. International Journal of Ethics \& Society (IJES), 2 (2):28-36.

27. Fayazi A, Naami A, Aghamusa R. (2021). Mapping customers' mind value to avoid pseudo needs in consuming drinks during flight based on ethical marketing approach. International Journal of Ethics \& Society (IJES), 2(4) :38-47. Doi: http://dx.doi.org/10.52547/ijethics.2.4.38 